\title{
Coalition formation among farsighted agents
}

Citation for published version (APA):

Herings, P. J. J., Mauleon, A., \& Vannetelbosch, V. (2010). Coalition formation among farsighted agents. METEOR, Maastricht University School of Business and Economics. METEOR Research Memorandum No. 025 https://doi.org/10.26481/umamet.2010025

Document status and date:

Published: 01/01/2010

DOI:

10.26481/umamet.2010025

Document Version:

Publisher's PDF, also known as Version of record

\section{Please check the document version of this publication:}

- A submitted manuscript is the version of the article upon submission and before peer-review. There can be important differences between the submitted version and the official published version of record.

People interested in the research are advised to contact the author for the final version of the publication, or visit the DOI to the publisher's website.

- The final author version and the galley proof are versions of the publication after peer review.

- The final published version features the final layout of the paper including the volume, issue and page numbers.

Link to publication

\footnotetext{
General rights rights.

- You may freely distribute the URL identifying the publication in the public portal. please follow below link for the End User Agreement:

www.umlib.nl/taverne-license

Take down policy

If you believe that this document breaches copyright please contact us at:

repository@maastrichtuniversity.nl

providing details and we will investigate your claim.
}

Copyright and moral rights for the publications made accessible in the public portal are retained by the authors and/or other copyright owners and it is a condition of accessing publications that users recognise and abide by the legal requirements associated with these

- Users may download and print one copy of any publication from the public portal for the purpose of private study or research.

- You may not further distribute the material or use it for any profit-making activity or commercial gain

If the publication is distributed under the terms of Article $25 \mathrm{fa}$ of the Dutch Copyright Act, indicated by the "Taverne" license above, 


\section{Maastricht University}

P. Jean-J acques Herings, Ana Mauleon, Vincent Vannetelbosch

\section{Coalition Formation among} Farsighted Agents

RM/ 10/025

\section{METEOR}

Maastricht University School of Business and Economics

Maastricht Research School of Economics

of Technology and Organization

\section{P.O. Box 616}

NL - 6200 MD Maastricht

The Netherlands 


\title{
Coalition Formation among Farsighted Agents ${ }^{\dagger}$
}

\author{
P. Jean-Jacques Herings ${ }^{\mathrm{a}}$, Ana Mauleon ${ }^{\mathrm{b}, \mathrm{c}}$, \\ Vincent Vannetelbosch ${ }^{\mathrm{c}}$ \\ ${ }^{\mathrm{a}}$ Department of Economics, Maastricht University, P.O. Box 616, 6200 MD, \\ Maastricht, The Netherlands. \\ ${ }^{b}$ FNRS and CEREC, Facultés universitaires Saint-Louis, Boulevard du Jardin \\ Botanique 43, B-1000 Brussels, Belgium. \\ ${ }^{\mathrm{c}}$ FNRS and CORE, Université catholique de Louvain, 34 voie du Roman Pays, \\ B-1348 Louvain-la-Neuve, Belgium.
}

April 29, 2010

\begin{abstract}
A set of coalition structures $P$ is farsightedly stable (i) if all possible deviations from any coalition structure $p$ belonging to $P$ to a coalition structure outside $P$ are deterred by the threat of ending worse off or equally well off, (ii) if there exists a farsighted improving path from any coalition structure outside the set leading to some coalition structure in the set, and (iii) if there is no proper subset of $P$ satisfying the first two conditions. A non-empty farsightedly stable set always exists. We provide a characterization of unique farsightedly stable sets of coalition structures and we study the relationship between farsighted stability and other concepts such as the largest consistent set and the von Neumann-Morgenstern farsightedly stable set. Finally, we illustrate our results by means of coalition formation games with positive spillovers.
\end{abstract}

Keywords: Coalition Formation, Farsighted Players, Stability.

\footnotetext{
${ }^{\dagger}$ E-mail addresses: P.Herings@algec.unimaas.nl (P. Jean-Jacques Herings), mauleon@fusl.ac.be (Ana Mauleon), vincent.vannetelbosch@uclouvain.be (Vincent Vannetelbosch).
} 


\section{Introduction}

Many social, economic and political activities are conducted by groups or coalitions of individuals. For example, consumption takes place within households or families; production is carried out by firms which are large coalitions of owners of different factors of production; workers are organized in trade unions or professional associations; public goods are produced within a complex coalition structure of federal, state, and local jurisdictions; political life is conducted through political parties and interest groups; and individuals belong to networks of formal and informal social clubs.

The formation of coalitions has been studied adopting either the cooperative game-theoretic approach or the noncooperative one. The cooperative approach has first proposed myopic notions of stability such as core-stability, $\beta$-stability or $\alpha$ stability (see Hart and Kurz [6]). These concepts assume that deviations cannot be countered by subsequent deviations. Then, farsighted notions of stability such as the von Neumann-Morgenstern farsightedly stable set or the largest consistent set have been proposed (see Chwe [4]). Farsightedness of the coalitions means that a coalition considers the possibility that, once it acts, another coalition might react, a third coalition might in turn react, and so on without limit. ${ }^{1}$

The noncooperative approach has proposed simultaneous or sequential games of coalition formation which are usually solved using the Nash equilibrium concept or one of its refinements. ${ }^{2}$ Bloch [2] has proposed a sequential coalition formation game which relies on the commitment assumption. Once some players have agreed to form a coalition, they are committed to remain in that coalition. They can neither leave the coalition nor propose to change it later on. Ray and Vohra [12] have generalized Bloch's game by allowing for an endogenous distribution of coalitional gains. How-

\footnotetext{
${ }^{1}$ Xue [14] has proposed the solution concepts of optimistic or conservative stable standards of behavior. It strengthens the farsightedness notion of the largest consistent set. A farsighted individual considers only the final outcomes that might result when making choices. But, an individual with perfect foresight considers also how final outcomes can be reached. That is, possible deviations along the way to the final outcomes should be considered. Barbera and Gerber [1] have proposed a solution concept for hedonic coalition formation games: durability. This concept assumes some form of maxmin behavior on the part of farsighted players.

${ }^{2}$ For the coalitional contingent threat situation, Mariotti [10] has defined an equilibrium concept: the coalitional equilibrium. Central to his concept is the notion of coalitional strategies and the similarity with subgame perfection (except that coalitions are formally treated as players).
} 
ever, sequential coalition formation games are quite sensitive to the exact coalition formation process. $^{3}$ In order to remedy the shortcomings of existing solution concepts and to identify the consequences of common knowledge of rationality, Herings, Mauleon and Vannetelbosch [7] have proposed to apply extensive-form rationalizability to the framework of social environments. A social environment constitutes a framework in which it is possible to study how groups of players interact in a society. On this social environment is defined a multi-stage game. An outcome of the social environment is socially rationalizable if and only if it is rationalizable in the multi-stage game. The set of socially rationalizable outcomes is shown to be non-empty for all social environments and it can be computed by an iterative reduction procedure. This noncooperative approach is very appealing but it can be hard to compute socially rationalizable outcomes. However, the cooperative notions of farsighted stability take into account the long run and farsightedly stable outcomes are less demanding in terms of computations.

The objective of this paper is to provide a new stability concept to predict which coalition structures are likely to emerge in the long run when coalition members are farsighted. A set of coalition structures $P$ is farsightedly stable (i) if all possible deviations from any coalition structure $p$ belonging to $P$ to a coalition structure outside $P$ are deterred by the threat of ending worse off or equally well off, (ii) if there exists a farsighted improving path from any coalition structure outside the set leading to some coalition structure in the set, and (iii) if there is no proper subset of $P$ satisfying the first two conditions. In contrast to other concepts incorporating farsightedness, we do not only request that all possible deviations out of the set are deterred by the threat of ending worse off, but also that there exists a farsighted improving path from any coalition structure outside the set leading to some coalition structure in the set. This property is equivalent to the requirement that coalition structures within the set are robust to perturbations. This new stability concept was originally defined by Herings, Mauleon and Vannetelbosch [8] for network formation models. In Herings, Mauleon and Vannetelbosch [8] the set of states was the set of networks and the possible moves from one network were restricted to pairwise deviations. Here, the set of states is the set of coalition structures and the possible moves from one coalition structure allow for coalitional deviations.

\footnotetext{
${ }^{3}$ Konishi and Ray [9] have studied a model of dynamic coalition formation where players evaluate the desirability of a move in terms of its consequences on the entire discounted stream of payoffs.
} 
A non-empty farsightedly stable set always exists. We provide a characterization of unique farsightedly stable sets of coalition structures. We have that any von Neumann-Morgenstern farsightedly stable set is also a farsightedly stable set. By means of examples, we show that farsightedly stable sets have no relationship to largest consistent sets. Finally, we apply our new concept to coalition formation games satisfying the properties of positive spillovers, negative association and efficiency of the grand coalition. We obtain that, contrary to myopic notions of stability, the set consisting of the grand coalition is always a farsightedly stable set.

The paper is organized as follows. In Section 2 we introduce some notations and basic notions of farsightedness. In Section 3 we define the notion of farsightedly stable sets of coalition structures. In Section 4 we illustrate our results by means of coalition formation games with positive spillovers. In Section 5 we conclude.

\section{Coalition formation}

The players are forming coalitions and inside each coalition formed the members share the coalitional gains from cooperation. Let $\mathbb{P}$ be the finite set of coalition structures. A coalition structure $p=\left\{S_{1}, S_{2}, \ldots, S_{m}\right\}$ is a partition of the player set $N=\{1,2, \ldots, n\}$, so $S_{i} \neq \varnothing$ for $i=1, \ldots, m, S_{i} \cap S_{j}=\varnothing$ for $i \neq j$, and $\bigcup_{i=1}^{m} S_{i}=N$. Let $\# S_{i}$ be the cardinality of coalition $S_{i}$. Gains from cooperation are described by a valuation $V$, a mapping from the set of coalition structures $\mathbb{P}$ into vectors of payoffs in $\mathbb{R}^{n}$. The component $V_{i}(p)$ denotes the payoff obtained by player $i$ if the coalition structure $p$ is formed.

How does the formation of coalitions proceed? A coalition structure $p^{\prime}$ is obtainable from $p$ via $T, T \subseteq N$, if (i) $\left\{S^{\prime} \in p^{\prime}: S^{\prime} \subseteq N \backslash T\right\}=\{S \backslash T: S \in p, S \backslash T \neq \emptyset\}$, and (ii) $\exists\left\{S_{1}^{\prime}, S_{2}^{\prime}, \ldots, S_{m}^{\prime}\right\} \subseteq p^{\prime}$ such that $\cup_{i=1}^{m} S_{i}^{\prime}=S$. Condition (i) means that if the players in $S$ leave their respective coalition(s) in $p$, the non-deviating players do not move. Condition (ii) allows the deviating players in $S$ to form one or several coalitions in the new status-quo $p^{\prime}$. Non-deviating players do not belong to those new coalitions.

The notion of farsighted improving path captures the fact that farsighted coalitions consider the end coalition structure that their move(s) may lead to. That is, a farsighted improving path is a sequence of coalition structures that can emerge when players form coalitions based on the improvement the end coalition structure 
offers relative to the current coalition structure.

Definition 1. A farsighted improving path from a coalition structure $p$ to a coalition structure $p^{\prime} \neq p$ is a finite sequence of coalition structures $p_{1}, \ldots, p_{K}$ with $p_{1}=p$ and $p_{K}=p^{\prime}$ such that for any $k \in\{1, \ldots, K-1\}, p_{k+1}$ is obtainable from $p_{k}$ via some coalition $S_{k}, V_{i}\left(p_{K}\right) \geq V_{i}\left(p_{k}\right)$ for all $i \in S_{k}$ and $V_{i}\left(p_{K}\right)>V_{i}\left(p_{k}\right)$ for some $i \in S_{k}$.

For a given coalition structure $p$, let $F(p)$ be the set of coalition structures that can be reached by a farsighted improving path from $p$. Two solution concepts are commonly used to predict which coalition structure will emerge when players are farsighted: the von Neumann-Morgenstern farsightedly stable set and the largest consistent set.

The von Neumann-Morgenstern stable set (von Neumann and Morgenstern [13]) imposes internal and external stability. Incorporating the notion of farsighted improving paths into the original definition of the von Neumann-Morgenstern stable set, we obtain the von Neumann-Morgenstern farsightedly stable set.

Definition 2. The set $P \subseteq \mathbb{P}$ is a von Neumann-Morgenstern farsightedly stable set if (i) $\forall p \in P, F(p) \cap P=\varnothing$ and (ii) $\forall p^{\prime} \in \mathbb{P} \backslash P, F\left(p^{\prime}\right) \cap P \neq \varnothing$.

However, a von Neumann-Morgenstern farsightedly stable set does not always exist as is shown in Example 1.

Example 1. Consider a coalition formation game among three players taken from Diamantoudi and Xue [5].
Partitions
Payoffs

Player 1 Player 2 Player 3

$\begin{array}{llll}\{123\} & 0 & 0 & 0 \\ \{12,3\} & 3 & 2 & 1 \\ \{13,2\} & 2 & 1 & 3 \\ \{23,1\} & 1 & 3 & 2 \\ \{1,2,3\} & 1 & 1 & 1\end{array}$

In this example, $\{12,3\}$ should be interpreted as the coalition structure where players 
1 and 2 are together and player 3 is alone. It can be verified that

$$
\begin{aligned}
F(\{123\}) & =\{\{12,3\},\{13,2\},\{23,1\},\{1,2,3\}\} \\
F(\{12,3\}) & =\{\{23,1\}\} \\
F(\{13,2\}) & =\{\{12,3\}\} \\
F(\{23,1\}) & =\{\{13,2\}\} \\
F(\{1,2,3\}) & =\{\{12,3\},\{13,2\},\{23,1\}\} .
\end{aligned}
$$

To satisfy external stability a set should include at least two coalition structures (for instance, $\{12,3\}$ and $\{13,2\}$ ), but then internal stability would be violated. It follows that there is no von Neumann-Morgenstern farsightedly stable set.

The largest consistent set is a concept that has been defined in Chwe [4].

Definition 3. The set $P \subseteq \mathbb{P}$ is a consistent set if for all $p \in P$, for all $S \subseteq N$, and for all $p^{\prime} \in \mathbb{P} \backslash\{p\}$, where $p^{\prime}$ is obtainable from $p$ via $S$, there exists $p^{\prime \prime} \in P$, where $p^{\prime \prime}=p^{\prime}$ or $p^{\prime \prime} \in F\left(p^{\prime}\right)$ such that we do not have $V_{i}(p) \leq V_{i}\left(p^{\prime \prime}\right)$ for all $i \in S$ and $V_{i}(p)<V_{i}\left(p^{\prime \prime}\right)$ for some $i \in S$. The largest consistent set is the consistent set that contains any consistent set.

Chwe [4] has shown that there uniquely exists a largest consistent set and has provided the following iterative procedure to find the largest consistent set. Let $Z^{0} \equiv \mathbb{P}$. Then $Z^{k}(k=1,2, \ldots)$ is inductively defined as follows: $p \in Z^{k-1}$ belongs to $Z^{k}$ if and only if $\forall p^{\prime} \in \mathbb{P} \backslash\{p\}, \forall S \subseteq N$ such that $p^{\prime}$ is obtainable from $p$ via $S$, $\exists p^{\prime \prime} \in Z^{k-1}$, where $p^{\prime}=p^{\prime \prime}$ or $p^{\prime \prime} \in F\left(p^{\prime}\right)$, such that we do not have $V_{i}(p) \leq V_{i}\left(p^{\prime \prime}\right)$ for all $i \in S$ and $V_{i}(p)<V_{i}\left(p^{\prime \prime}\right)$ for some $i \in S$. The largest consistent set is given by $\bigcap_{k \geq 1} Z^{k}$.

Example 2. Consider a coalition formation game among four players where payoffs are obtained from a model of pure public goods coalitions with congestion (see Mauleon and Vannetelbosch [11]). Later on we will consider a model of pure public goods without congestion in more detail.

\section{Partitions Payoffs}

Player 1 Player 2 Player $3 \quad$ Player 4

6
4
5
3
3.5

6

6

4

5

3

3.5

3.5

$$
6
$$

$$
5
$$


The payoffs for other coalition structures follow by symmetry. It can be verified that

$$
\begin{aligned}
& F(\{1234\})=\{\{123,4\},\{124,3\},\{134,2\},\{234,1\}\}, \\
& F(\{123,4\})=\left\{\begin{array}{l}
\{1234\},\{124,3\},\{134,2\},\{234,1\},\{12,34\},\{13,24\}, \\
\{14,23\},\{12,3,4\},\{13,2,4\},\{23,1,4\}
\end{array}\right\}, \\
& F(\{124,3\})=\left\{\begin{array}{l}
\{1234\},\{123,4\},\{134,2\},\{234,1\},\{12,34\},\{13,24\}, \\
\{14,23\},\{12,3,4\},\{14,2,3\},\{24,1,3\}
\end{array}\right\}, \\
& F(\{134,2\})=\left\{\begin{array}{l}
\{1234\},\{124,3\},\{123,4\},\{234,1\},\{12,34\},\{13,24\}, \\
\{14,23\},\{13,2,4\},\{14,2,3\},\{34,1,2\}
\end{array}\right\}, \\
& F(\{234,1\})=\left\{\begin{array}{l}
\{1234\},\{124,3\},\{134,2\},\{123,4\},\{12,34\},\{13,24\}, \\
\{14,23\},\{23,1,4\},\{24,1,3\},\{34,1,2\}
\end{array}\right\},
\end{aligned}
$$

$$
\begin{aligned}
& F(\{12,34\})=\{\{1234\},\{123,4\},\{124,3\},\{134,2\},\{234,1\},\{12,3,4\},\{34,1,2\}\}, \\
& F(\{13,24\})=\{\{1234\},\{123,4\},\{124,3\},\{134,2\},\{234,1\},\{13,2,4\},\{24,1,3\}\}, \\
& F(\{14,23\})=\{\{1234\},\{123,4\},\{124,3\},\{134,2\},\{234,1\},\{14,2,3\},\{23,1,4\}\}, \\
& F(\{12,3,4\})=\left\{\begin{array}{l}
\{1234\},\{123,4\},\{124,3\},\{134,2\},\{234,1\},\{12,34\}, \\
\{13,24\},\{14,23\},\{1,2,3,4\}
\end{array}\right\} \\
& =F(\{13,2,4\})=F(\{14,2,3\})=F(\{23,2,4\})=F(\{24,1,3\}) \\
& =F(\{34,1,2\}) \text {, } \\
& F(\{1,2,3,4\})=\left\{\begin{array}{l}
\{1234\},\{123,4\},\{124,3\},\{134,2\},\{234,1\},\{12,34\}, \\
\{13,24\},\{14,23\}
\end{array}\right\} .
\end{aligned}
$$

In the first round of the iterative procedure to compute the largest consistent set, we eliminate the coalition structures $\{1,2,3,4\},\{12,3,4\},\{13,2,4\},\{14,2,3\}$, $\{23,1,4\},\{24,1,3\}$, and $\{34,1,2\}$. Indeed, the deviations from $\{1,2,3,4\}$ to $\{1234\}$ and from $\{12,3,4\}$ (or $\{13,2,4\}$ or $\{14,2,3\}$ or $\{23,1,4\}$ or $\{24,1,3\}$ or $\{34,1,2\}$ ) to $\{1,2,3,4\}$ are not deterred. We cannot eliminate other coalition structures since any possible deviations from $\{1234\}$ or $\{123,4\}$ or $\{124,3\}$ or $\{134,2\}$ or $\{234,1\}$ or $\{12,34\}$ or $\{13,24\}$ or $\{14,23\}$ are deterred. For example, the deviations from either $\{123,4\}$ or $\{12,34\}$ to $\{12,3,4\}$ by player 3 are deterred since $\{123,4\} \in F(\{12,3,4\})$ with the original deviating player obtaining again 4 as payoff. In the second round, we cannot eliminate other coalition structures since any possible deviations from $\{1234\}$ or $\{123,4\}$ or $\{124,3\}$ or $\{134,2\}$ or $\{234,1\}$ or $\{12,34\}$ or $\{13,24\}$ or $\{14,23\}$ are still deterred. Therefore, the largest consistent set is $\{\{1234\},\{123,4\},\{124,3\},\{134,2\},\{234,1\},\{12,34\},\{13,24\},\{14,23\}\}$. 
So $\{12,34\},\{13,24\}$ and $\{14,23\}$ belong to the largest consistent set even though they are Pareto dominated by $\{1234\}$.

\section{$3 \quad$ Farsightedly stable sets of coalition structures}

We now give the definition of a farsightedly stable set of coalition structures. This concept was originally defined by Herings, Mauleon and Vannetelbosch [8] for network formation models with pairwise deviations.

Definition 4. The set $P \subseteq \mathbb{P}$ is a farsightedly stable set if

(i) $\forall p \in P, \forall p^{\prime} \notin P$ such that $p^{\prime}$ is obtainable from $p$ via $S \subseteq N, \exists p^{\prime \prime} \in F\left(p^{\prime}\right) \cap P$ such that we do not have $V_{i}(p) \leq V_{i}\left(p^{\prime \prime}\right)$ for all $i \in S$ and $V_{i}(p)<V_{i}\left(p^{\prime \prime}\right)$ for some $i \in S$.

(ii) $\forall p^{\prime} \in \mathbb{P} \backslash P, F\left(p^{\prime}\right) \cap P \neq \varnothing$.

(iii) $\nexists P^{\prime} \varsubsetneqq P$ such that $P^{\prime}$ satisfies Conditions (i) and (ii).

Condition (i) in Definition 4 requires the deterrence of external deviations. It captures that any deviation to a coalition structure outside of $P$, is deterred by the threat of ending in $p^{\prime \prime}$. Here $p^{\prime \prime}$ is such that there is a farsighted improving path from $p^{\prime}$ to $p^{\prime \prime}$. Moreover, $p^{\prime \prime}$ belongs to $P$, which makes $p^{\prime \prime}$ a credible threat. Condition (ii) in Definition 4 requires external stability and implies that the coalition structures within the set are robust to perturbations. From any coalition structure outside of $P$ there is a farsighted improving path leading to some coalition structure in $P$. Condition (ii) implies that if a set of coalition structures is farsightedly stable, it is non-empty. Notice that the set $\mathbb{P}$ (trivially) satisfies Conditions (i) and (ii) in Definition 4. This motivates the requirement of a minimality condition, namely Condition (iii).

Proposition 1. A farsightedly stable set of coalition structures exists.

All the proofs not in the main text are directly obtained from those in Herings, Mauleon and Vannetelbosch [8]. Replacing the internal stability condition in the von Neumann-Morgenstern farsightedly stable set by deterrence of external deviations and minimality, leads to a stability concept that is always non-empty. We now provide an easy to verify condition for a set $P$ to be farsightedly stable. 
Proposition 2. If for every $p^{\prime} \in \mathbb{P} \backslash P$ we have $F\left(p^{\prime}\right) \cap P \neq \varnothing$ and for every $p \in P$, $F(p) \cap P=\varnothing$, then $P$ is a farsightedly stable set.

A coalition structure $p$ is core-stable if for any $S \subseteq N, p^{\prime} \in \mathbb{P}$ that is obtainable from $p$ via $S$ and $i \in S$ such that $V_{i}\left(p^{\prime}\right)>V_{i}(p)$, there exists $j \in S$ such that $V_{j}\left(p^{\prime}\right)<V_{j}(p)$. Proposition 2 implies that if $P$ is the unique farsightedly stable set and the coalition structure $p$ belongs to $P$, then $F(p)=\varnothing$, which implies that $p$ is core-stable. Thus, farsighted stability is a refinement of core-stability when there is a unique farsightedly stable set. From Proposition 2 it is immediate that if $P$ is a von Neumann-Morgenstern farsightedly stable set, then $P$ is a farsightedly stable set.

Proposition 3. The set $\{p\}$ is a farsightedly stable set if and only if for every $p^{\prime} \in \mathbb{P} \backslash\{p\}$ we have $p \in F\left(p^{\prime}\right)$.

This proposition tells us that $\{p\}$ is a farsightedly stable set if and only if there exists a farsighted improving path from any coalition structure leading to $p$. Condition (iii) implies that if $\{p\}$ is a farsightedly stable set, then $p$ does not belong to any other farsightedly stable set. But there may be farsightedly stable sets not containing $p$.

Since internal stability is automatically satisfied when a set of coalition structures contains only one element, we have from Proposition 3 that the set $\{p\}$ is a farsightedly stable set if and only if it is a von Neumann-Morgenstern farsightedly stable set.

Proposition 4. The set $P$ is the unique farsightedly stable set if and only if $P=$ $\{p \in \mathbb{P} \mid F(p)=\varnothing\}$ and for every $p^{\prime} \in \mathbb{P} \backslash P, F\left(p^{\prime}\right) \cap P \neq \varnothing$.

From Proposition 4 we immediately get the next result: if $P$ is the unique farsightedly stable set, then $P$ is the unique von Neumann-Morgenstern farsightedly stable set.

Corollary 1. The set $\{p\}$ is the unique farsightedly stable set if and only if for every $p^{\prime} \in \mathbb{P} \backslash\{p\}$ we have $p \in F\left(p^{\prime}\right)$ and $F(p)=\varnothing$.

If for every $p^{\prime} \in \mathbb{P} \backslash\{p\}$ we have $p \in F\left(p^{\prime}\right)$, then $\{p\}$ is a farsightedly stable set. If, moreover, $F(p)=\varnothing$, then $\{p\}$ is the unique farsightedly stable set. If, on the other hand, $F(p) \neq \varnothing$, then there is another farsightedly stable set. 
Example 3. Consider a coalition formation game among four players where payoffs are obtained from a cartel formation game (see Mauleon and Vannetelbosch [11]). Partitions Payoffs

Player 1 Player 2 Player 3

$\begin{array}{cccc}\{123\} & 12 & 12 & 12 \\ \{12,3\} & 8 & 8 & 16 \\ \{13,2\} & 8 & 16 & 8 \\ \{23,1\} & 16 & 8 & 8 \\ \{1,2,3\} & 9 & 9 & 9\end{array}$

We have

$$
\begin{aligned}
F(\{123\}) & =\{\{12,3\},\{13,2\},\{23,1\}\}, \\
F(\{12,3\}) & =F(\{13,2\})=F(\{23,1\})=\{\{123\},\{1,2,3\}\}, \\
F(\{1,2,3\}) & =\{\{123\}\} .
\end{aligned}
$$

The set $\{\{123\}\}$ is a farsightedly stable set, though not the unique one since $F(\{123\}) \neq \varnothing$. The set $P=\{\{12,3\},\{13,2\},\{23,1\},\{1,2,3\}\}$ also constitutes a farsightedly stable set. Thus, any deviation to a coalition structure outside $P$ is deterred and from any coalition structure outside of $P$ there is a farsighted improving path going into $P$. It is easy to verify that a subset of $P$ would not satisfy Condition (ii) of the definition of a farsightedly stable set.

In Example 1 there is no von Neumann-Morgenstern farsightedly stable set. Moreover, there is no $p$ such that $F(p)=\varnothing$. Hence, there is more than one farsightedly stable set. In fact, $\{\{12,3\},\{13,2\}\},\{\{13,2\},\{23,1\}\}$, and $\{\{12,3\},\{23,1\}\}$ are the farsightedly stable sets. In Example 2 we have more than one farsightedly stable set since there is no $p$ such that $F(p)=\varnothing$. It can be verified that $\{\{1234\}\}$, $\{\{123,4\}\},\{\{124,3\}\},\{\{134,2\}\}$, and $\{\{234,1\}\}$ are the farsightedly stable sets of coalition structures.

The next proposition tells us that if a coalition structure does not belong to the largest consistent set, it cannot be a farsightedly stable set of coalition structures.

Proposition 5. If $\{p\}$ is a farsightedly stable set, then $p$ belongs to the largest consistent set.

There is no general relationship between the largest consistent set and farsightedly stable sets. Example 2 shows that the largest consistent set may contain other 
coalition structures. The coalition structures $\{12,34\},\{13,24\}$ and $\{14,23\}$ belong to the largest consistent set but do not belong to any farsightedly stable set. However, Example 3 shows that farsightedly stable sets may contain other coalition structures too. Indeed, the set $P=\{\{12,3\},\{13,2\},\{23,1\},\{1,2,3\}\}$ is a farsightedly stable set, but none of the coalition structures belonging to $P$ do belong to the largest consistent set. Indeed, the largest consistent set singles out the grand coalition $\{N\}$.

\section{Coalition formation with positive spillovers}

Gains are assumed to be positive, $V_{i}(p)>0$ for all $i \in N$, for all $p \in \mathbb{P}$. We consider $n \geq 3$. We assume symmetric or identical players and equal sharing of the coalitional gains among coalition members. ${ }^{4}$ That is, in any coalition $S_{i}$ belonging to $p, V_{j}(p)=V_{l}(p)$ for all $j, l \in S_{i}, i=1, \ldots, m$. So, let $V\left(S_{i}, p\right)$ denote the payoff obtained by any player belonging to $S_{i}$ in the coalition structure $p$. We focus on coalition formation games satisfying the following conditions on the per-member payoffs.

(P.1) Positive Spillovers. $V\left(S_{i},\left(p \backslash\left\{S_{1}, S_{2}\right\}\right) \cup\left\{S_{1} \cup S_{2}\right\}\right)>V\left(S_{i}, p\right)$ for all players belonging to $S_{i}, S_{i} \neq S_{1}, S_{2}$.

Condition (P.1) restricts our analysis to games with positive spillovers, where the formation of a coalition by other players increases the payoff of a player.

(P.2) Negative Association. $V\left(S_{i}, p\right)<V\left(S_{j}, p\right)$ if and only if $\left|S_{i}\right|>\left|S_{j}\right|$.

Condition (P.2) imposes that, in any coalition structure, small coalitions have higher per-member payoffs than big coalitions.

(P.3) Efficiency. $\forall p=\left\{S_{1}, S_{2}, \ldots, S_{m}\right\} \in \mathbb{P} \backslash\{N\}$ it holds that $\sum_{i=1}^{m} \# S_{i} V\left(S_{i}, p\right)<$ $n V(N,\{N\})$.

\footnotetext{
${ }^{4}$ Ray and Vohra [12] have provided a justification for the assumption of an equal sharing rule. In an infinite-horizon model of coalition formation among symmetric players with endogenous bargaining, they have shown that in any equilibrium without delay there is equal sharing.
} 
Finally, condition (P.3) assumes that the grand coalition is the only efficient coalition structure with respect to payoffs.

A first economic situation satisfying the three conditions is a cartel formation game with Cournot competition as in Bloch [3] and Yi [15]. Let $\pi(q)=a-q$ be the inverse demand ( $q$ is the industry output). The industry consists of $n$ identical firms. Inside each cartel, we assume equal sharing of the benefits obtained from the cartel's production. Once stable agreements on cartel formation have been reached, we observe a Cournot competition among the cartels. The payoff for each firm in each possible coalition structure is well defined. Firm $i$ 's cost function is given by $c q_{i}$, where $q_{i}$ is firm $i$ 's output and $c(a>c)$ is the common constant marginal cost. As a result, the per-member payoff in a cartel of size \#S is

$$
V(S, p)=\frac{(a-c)^{2}}{\# S(\# p+1)^{2}},
$$

where $\# p$ is the number of cartels within $p$. Output cartels in a Cournot oligopoly with the inverse demand function $\pi(q)=a-q$ and the cost function $c\left(q_{i}\right)=c q_{i}$ satisfy (P.1)-(P.3). Yi [15] has shown that conditions (P.1) and (P.2) are satisfied. It is straightforward to show that (P.3) is also satisfied.

A second economic situation satisfying the three conditions are economies with pure public goods. The economy consists of $n$ agents. At cost $c_{i}\left(q_{i}\right)$, agent $i$ can provide $q_{i}$ units of the public good. Let $q=\sum_{i} q_{i}$ be the total amount of public good. The utility each agent obtains from the public good depends positively on the total amount of public good provided: $U_{i}(q)=q$ for all $i \in N$. Each agent owns a technology to produce the public good, and the cost of producing the amount $q_{i}$ of the public good is given by $c_{i}\left(q_{i}\right)=\frac{1}{2}\left(q_{i}\right)^{2}$. Since individual cost functions are convex and exhibit decreasing returns to scale, it is cheaper to produce an amount $q$ of public goods using all technologies than by using a single technology. In stage one the coalition formation takes place. Inside each coalition, we assume equal sharing of the production. Once a coalition structure has been formed, each coalition of agents acts noncooperatively. On the contrary, inside every coalition, agents act cooperatively and the level of public good is chosen to maximize the sum of utilities of the coalition members. That is, for any coalition structure $p=\left\{S_{1}, S_{2}, \ldots, S_{m}\right\}$, the level of public good $q_{S_{i}}$ chosen by the coalition $S_{i}$ solves

$$
\max _{q_{S_{i}}} \# S_{i}\left(q_{S_{i}}+\sum_{j \neq i} q_{S_{j}}-\frac{1}{2}\left(\frac{q_{S_{i}}}{\# S_{i}}\right)^{2}\right)
$$


yielding a total level of public good provision for the coalition $S_{i}$ equal to $q_{S_{i}}=$ $\left(\# S_{i}\right)^{2}, i=1, \ldots, m$. The per-member payoff in a coalition of size $\# S_{i}$ is given by

$$
V\left(S_{i}, p\right)=\sum_{j=1}^{m}\left(\# S_{j}\right)^{2}-\frac{1}{2}\left(\# S_{i}\right)^{2},
$$

for all agents belonging to $S_{i}, i=1, \ldots, m$. Yi [15] has shown that conditions (P.1) and (P.2) are again satisfied. It is straightforward to show that (P.3) is also satisfied.

A set consisting of the grand coalition structure $\{N\}$ only, the efficient coalition structure, is a farsightedly stable set.

Proposition 6. Under (P.1)-(P.3), $\{\{N\}\}$ is a farsightedly stable set.

Proof. To prove that $\{\{N\}\}$ is a farsightedly stable set, we have to show that for all $p \neq\{N\}$ we have $\{N\} \in F(p)$. The proof is done in two steps.

Step A. Since the per-member payoffs satisfy negative association and efficiency of the grand coalition, the players belonging to the coalition with the highest number of members in any $p$ different from $\{N\}$ are worse off than in $\{N\}$. Also, all players prefer $\{N\}$ to $\bar{p}=\left\{S_{1}, \ldots, S_{n}\right\}$ with $\# S_{i}=1$ for all $S_{i} \in \bar{p}$. Step B. Take the sequence of moves where at each move one player belonging to the biggest coalition in the current coalition structure deviates to form a singleton, until the coalition structure $\bar{p}$ is reached. From $\bar{p}$ the grand coalition deviates to $\{N\}$. By $(A)-(B)$ we have that $\{N\} \in F(p)$ for all $p \neq\{N\}$.

However, it may be that $\{\{N\}\}$ is not the unique farsightedly stable set of coalition structures. In the cartel formation game, $\{\{N\}\}$ is not the unique farsightedly stable set for $n \geq 3$. Mauleon and Vannetelbosch [11] have shown that the grand coalition structure $\{N\}$ always belongs to the largest consistent set, and is possibly stable by itself. For instance, the largest consistent set singles out the grand coalition $\{N\}$ for $n \leq 4$. But as \#N grows, many coalition structures may belong to the largest consistent set. In the public good game, the set $\{\{N\}\}$ is not the unique farsightedly stable set when $n \geq 4$. Finally, notice that the set $\{\{N\}\}$ is also a von Neumann-Morgenstern farsightedly stable set. Hence, under (P.1)-(P.3), the grand coalition is a farsightedly stable set, a von Neumann-Morgenstern farsightedly stable set, and belongs to the largest consistent set.

Finally, notice that in both the cartel formation game and in the public good game, core-stability, $\alpha$-stability, $\beta$-stability and Bloch's sequential game do not select the grand coalition (see Bloch [2]). For instance, any symmetric stationary 
perfect equilibria of Bloch's sequential game of cartel formation only support cartel structures $p=\left\{S_{1}^{*}, S_{2}^{*}, \ldots, S_{m}^{*}\right\}$ where $\# S_{1}^{*}$ is the first integer following $(2 n+3-$ $\sqrt{4 n+5}) / 2$ and $\# S_{j}^{*}=1$ for $j=2, \ldots, m$.

\section{Conclusion}

We have proposed a concept, farsighted stable set of coalition structures, to predict which coalition structures may be formed among farsighted players. A set of coalition structures $P$ is farsightedly stable (i) if all possible deviations from any coalition structure $p$ belonging to $P$ to a coalition structure outside $P$ are deterred by the threat of ending worse off or equally well off, (ii) if there exists a farsighted improving path from any coalition structure outside the set leading to some coalition structure in the set, and (iii) if there is no proper subset of $P$ satisfying Conditions (i) and (ii). A non-empty farsightedly stable set always exists. We have provided a characterization of unique farsightedly stable sets of coalition structures and we have studied the relationship between farsighted stability and other concepts such as the largest consistent set and the von Neumann-Morgenstern farsightedly stable set. Any von Neumann-Morgenstern farsightedly stable set belongs to the largest consistent set and is a farsightedly stable set. By means of examples we have shown that there is no general relationship between farsightedly stable sets and the largest consistent set. Finally, we have illustrated our results by analyzing coalition formation games with positive spillovers.

\section{Acknowledgments}

Vincent Vannetelbosch and Ana Mauleon are Research Associates of the National Fund for Scientific Research (FNRS). Financial support from Spanish Ministry of Sciences and Innovation under the project ECO 2009-09120, support from the Belgian French Community's program Action de Recherches Concertée 05/10-331, and support of a SSTC grant from the Belgian Federal government under the IAP contract P6/09 are gratefully acknowledged.

\section{References}

[1] Barbera, S.; Gerber, A. On Coalition Formation: Durable Coalition Structures. Math. Soc. Sciences 2003, 45, 185-203. 
[2] Bloch, F. Sequential Formation of Coalitions in Games with Externalities and Fixed Payoff Division. Games Econ. Behav. 1996, 14, 90-123.

[3] Bloch, F.. Non-Cooperative Models of Coalition Formation in Games with Spillovers, in New Directions in the Economic Theory of the Environment (C. Carraro and D. Siniscalco, Eds.), pp.311-352, Cambridge University Press: Cambridge, UK, 1997.

[4] Chwe, M.S. 1994. Farsighted Coalitional Stability. J. Econ. Theory 1994, 63, 299-325.

[5] Diamantoudi, E.; Xue, L. Farsighted Stability in Hedonic Games. Soc. Choice Welfare 2003, 21, 39-61.

[6] Hart, S.; Kurz, M. Endogenous Formation of Coalitions. Econometrica 1983, $51,1047-1064$.

[7] Herings, P.J.J.; Mauleon, A.; Vannetelbosch, V. Rationalizability for Social Environments. Games Econ. Behav. 2004, 49, 135-156.

[8] Herings, P.J.J.; Mauleon, A.; Vannetelbosch, V. Farsightedly Stable Networks. Games Econ. Behav. 2009, 67, 526-541.

[9] Konishi, H.; Ray, D. Coalition Formation as a Dynamic Process. J. Econ. Theory 2003, 110, 1-41.

[10] Mariotti, M. A Model of Agreements in Strategic Form Games. J. Econ. Theory 1997, 74, 196-217.

[11] Mauleon, A.; Vannetelbosch, V. Farsightedness and Cautiousness in Coalition Formation Games with Positive Spillovers. Theory and Decis. 2004, 56, 291324.

[12] Ray, D.; Vohra, R. A Theory of Endogenous Coalition Structures. Games Econ. Behav. 1999, 26, 286-336.

[13] von Neumann, J.; Morgenstern, O. Theory of Games and Economic Behavior. Princeton University Press: Princeton, NJ, USA, 1944.

[14] Xue, L. Coalitional Stability under Perfect Foresight. Econ. Theory 1998, 11, 603-627. 
[15] Yi, S.S. Stable Coalition Structures with Externalities. Games Econ. Behav. 1997, 20, 201-237. 